kinds of evidence than are presented in any recent general ecology text; here the reader will learn about overt aggression, overdispersion of colonies, overdispersion and complementarity of traits, exclusion experiments, packing experiments, natural and experimental introductions, and several instances in which introduced species have subsequently evolved reduced levels of aggression.

In the next four chapters, the authors consider the symbiotic relationships of ants with one another, with other arthropods, and with plants. Again, general principles are stressed, but not at the expense of natural history. Then follow five chapters on the evolution and ecology of the most distinctive ant lifestyles: the specialized predators, the army ants, the fungus growers, the seed harvesters and the weaver ants. A final short chapter describes various techniques for collecting ants and for culturing them in the laboratory.

Only Hölldobler and Wilson could have written such a comprehensive and integrated treatment of ant biology. It represents a herculean labour of love, and it sets a new standard for synthetic works on major taxa. Every expert will find something to complain about; each of us has a list of quibbles concerning overlooked literature, misplaced emphasis or questionable interpretations of evidence, in those particular areas we happen to master. But such flaws are inevitable in any book that attempts to organize a large and complex field, and they do not detract from its value in any important way. Like a social-insect colony, The Ants is much more than the sum of its parts. (Incidentally, why entire ant colonies behave in ways that are far more precise and reliable than the behaviours of individual workers is explained in chapter 9.)

The Ants can be viewed as a sequel to Wilson's The Insect Societies. Published nearly 20 years ago, that book was a similarly ambitious synthesis of natural history, experimental ecology, physiology and evolutionary theory. It convinced several generations of graduate students that the termites and the social Hymenoptera (ants, bees and wasps) are inherently fascinating organisms, and that they can be used very effectively to address fundamental issues in behaviour, ecology and evolution. Despite its age, The Insect Societies is still in print and still invaluable; our well-worn copies are always close at hand. Like its predecessor, The Ants will undoubtedly remain in active service for decades, guiding both tourists and seasoned travellers through a strange and wonderful world.

Donald H. Feener Jr, Diane W. Davidson and Jon Seger are in the Department of Biology, University of Utah, Salt Lake City, Utah 84112, USA

NATURE $\cdot$ VOL $344 \cdot 26$ APRIL 1990

\section{Guardian of the gates}

\section{Steven Dickman}

The Cuckoo's Egg. By Clifford Stoll. Bodley Head: 1990. Pp. 326. £12.95. Published in the United States by Doubleday: 1989. \$19.95, and in Germany by Fischer: 1990. DM29.80.

People who break into computers no longer do it just for fun. What used to be a diversion for lonely teenage savants has now become big business for criminals and spies.

A case in point was when West German 'hackers' - as these computer burglars have come to be called - in 1986 and 1987 broke into a number of United States

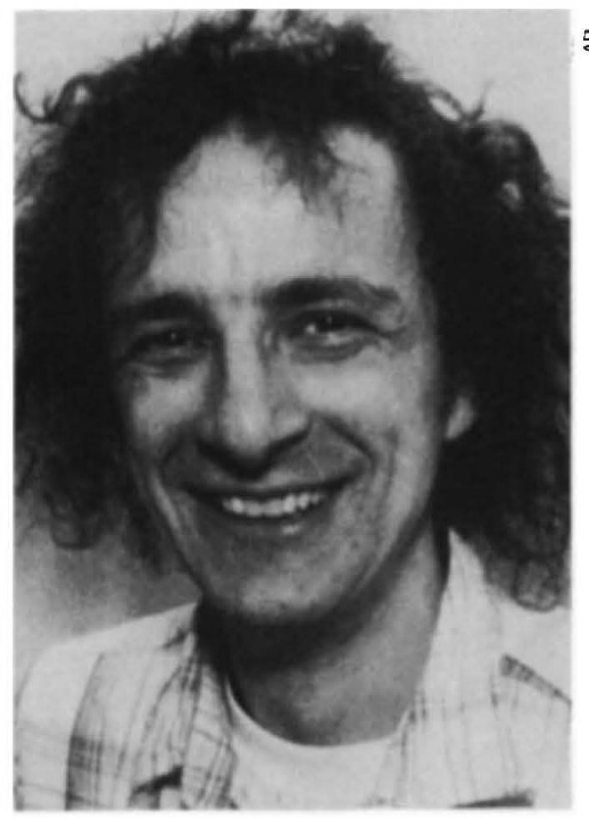

Stoll - ebullient charm.

military and academic computers. Gaining access through open academic networks, the hackers penetrated supposedly secure computers at US defence contractors and at military bases from Alabama to West Germany to Okinawa.

Although the hackers may have begun with innocent motivations, they quickly discovered that computer crime does pay, especially when military secrets are at stake. Until they were arrested in 1989, the hackers 'earned' DM90,000 (about $\$ 53,000)$ for delivering information to the KGB.

In the end, not that much damage was done to US national security; none of the information the hackers stole turned out to be classified. But the psychological damage was immense. For most computer users, military or otherwise, the thought of having intruders tromping through data files or changing the operating system are enough to bring on a cold sweat.
Fortunately, the individual user has an ally in fighting the battle for computer security - Clifford Stoll, a mopheaded astronomer-turned-computer-sleuth with a weakness for chocolate-chip cookies. Just a week after starting a job as a computer jack-of-all-trades at Lawrence Berkeley Laboratories in California (where, Stoll says, they "recycle used astronomers"), he was confronted with an accounting problem: the internal records showed an error of 75 cents. He thought it might take an afternoon to locate the source of the error. But when it became clear what was at stake, Stoll stayed up at night for two years, tracking a professional intruder nine time zones away who was rifling through dozens of computer systems.

Stoll narrates the tale of the chase in his fast-paced book The Cuckoo's Egg, from the first puzzling day when the computer's books did not balance until the triumph more than two years later when a hacker (and later his accomplices) was arrested in Hannover, West Germany, and charged with espionage. Stoll's editors must have faced a tough decision when they read his unique jargon-laced prose: whether to clean up the hippy, computer and California slang in the interests of clarity, or to leave it to the reader to make sense of it.

They chose the latter, allowing Stoll's ebullient personality to shine through. The British publishers have left the vocabulary alone, a decision that might leave non-technical (or non-US) readers justifiably perplexed by words like 'grinch' and 'kludge'. But despite a few rough spots, even someone completely 'computer-illiterate' will be able to follow the chase.

Much of the book's charm lies in Stoll's apparently unembellished descriptions of his extracurricular activities as an overage hippy in Berkeley - knitting quilts, going to costume parties, bicycling in the rain and drying his sneakers in the microwave oven. In between the anecdotes and the chocolate-chip cookie recipes, Stoll describes in painstaking detail how he made hacker-hunting a science, complete with lab notebook, scientific meetings and publications. His detailed records became valuable documents that were later used to reconstruct the break-ins before a West German court, where the hackers were eventually convicted of espionage.

Despite his continuing reluctance to identify himself as anything but an astronomer, Stoll belongs to a new - and necessary - breed of public servant: the hacker tracker. In his book, he reveals how little anyone - users, network managers, even intelligence agencies, had thought about security. Because of his efforts and the publicity they attracted, Stoll himself has already brought about some improvements in the system.

Military networks, recognizing that the 
stakes have been raised, are responding to the threat by installing new techniques such as a form of caller identification as well as simply by cutting themselves off from the outside world - the ultimate in computer security. Some businesses and scientific institutions are following suit.

But academic computer systems, especially those which offer on-line access to remote users, still face some difficult decisions. In some operating systems, increasing security necessarily means restricting access, which defeats the purpose of open networks. Clifford Stoll and his fellow guardians of the gates will have their hands full in the coming years in finding a happy medium.

Steven Dickman is Munich Correspondent of Nature.

for computer buffs. It is an analysis of business opportunities in the evolving world of information technology. It is, above all, about market forces and the contrasting responses to these forces on both sides of the Atlantic. In this respect, it gives a series of case studies in technical and marketing strategy that should appeal to a wide audience. If the office-appliance industry was the barometer of the economy in the mid-1920s, its successor - the information-technology industry - will certainly be the economic barometer of the 1990s. Economic forecasters should read this book, heed its lessons and advise management accordingly.

THE British computer industry, like the British car industry, is now firmly established as fair game for comment in saloon bars across the land. There are other similarities: computers, like cars, affect us all, and, as both products struggle to become more user-friendly, familiarity breeds contempt. Martin Campbell-Kelly's scholarly history of ICL (International Computers Ltd) pulls us up sharply. ICL is, for all practical purposes, the United Kingdom's only major computer company. It deserves to be taken seriously.

ICL has its origins in two punched-card office equipment firms: the British Tabulating Machine Company and the Accounting and Tabulating Machine Company (later PowersSamas). Although the heyday of the punched-card machine came during the 1930 s, this style of equipment saw service from the turn of the century through to the early 1960 s. Indeed ICT, the successor company

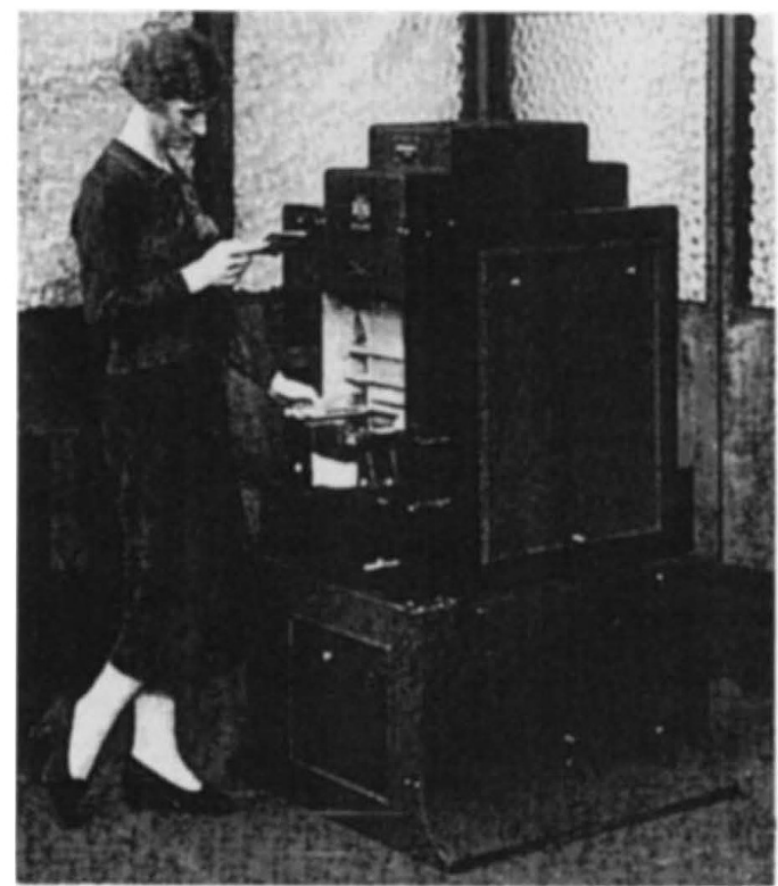
to BTM and the Acc and Tab, was still making 85 per cent of its money from the sale of punched-card equipment in 1960. It is therefore not surprising that the general-purpose computer does not come into the picture until well over half-way through this book. Computer buffs will want to skip the first 50 years of history and start at the point when the fondly remembered British computer manufacturers such as Elliott Brothers, English Electric and Ferranti became involved in the series of mergers with ICT that led to the formation of ICL.

This book is not, however, written value of all manner of office and computing equipment from 1908 to 1985 . These are always set in context, with comparative figures being presented for US and, latterly, continental European manufacturers. Through these figures we see the company's fortunes periodically rise and fall. To be fair to ICL, computer market trends have been notoriously difficult to predict. There is the oft-quoted remark of an undisputed computer expert, Professor Douglas Hartree, in conversation with 'the' Ferranti computer salesman in September 1951: "We have a computer here in Cambridge; there is one in Manchester and one at the NPL. I suppose there ought to be one in Scotland, but that's about all."

If 'scholarly' is the natural adjective to describe this book, what qualifications are demanded of its readers? They certainly need to be computer literate, not only to overcome the modest number of technical terms encountered here but also, more importantly, to appreciate the differences in power and scope of the various computing systems mentioned by CampbellKelly. This is especially true of ICL's developments since 1970 , as the company struggled with the technical complexities of its "new range". The architecture of this new range is, in the words of CampbellKelly, "masterly and in advance of anything offered by any other manufacturer". We are not told why. Similarly, two very innovative ICL ideas - the distributed array processor and the content-addressable file store - are left dangling in the text in much the same way as the projects were left dangling for years within ICL before being presented in a realistic way to the market place. This book is thus technically tight-lipped.

For those with a taste for the technical, the book nevertheless contains some appetizing morsels. For example, there is the accounting machine invented by the Spaniard F. P. Campos in 1923. Containing 1,000 registers, it also offered Babbage-like possibilities for mathematical computation - if only it could have been made to operate reliably. There is also the important work done by the British Tabulating Machine Company for the 1939-45 war effort at Bletchley Park. Finally, there is the innovative work done by Ferranti and at Manchester University in connection with the Atlas computer which became operational in 1962. It is interesting to note that the ex-Ferranti West Gorton factory and Manchester University have again combined to provide much of the input to ICL's latest research project: a novel parallel computer called EDS, the European declarative system.

Simon Lavington is in the Department of Computer Science, University of Essex, Wivenhoe Park, Colchester CO4 3SQ, UK. 